Esti Mulyani ${ }^{1)}$, Eka Ismantohadi' ${ }^{2),}$ Koriah $^{3)}$

Informatika : Fakultas Sains dan Teknologi

Universitas Labuhanbatu

Vol. 8 No.1 / Januari/2020

2615-1855 (E-ISSN)

2303-2863 (P-ISSN)

\title{
SISTEM PREDIKSI POTENSI DROP OUT MAHASISWA MENGGUNAKAN RULE BASED SYSTEM PADA JURUSAN TEKNIK INFORMATIKA POLITEKNIK NEGERI INDRAMAYU
}

\author{
Esti Mulyani ${ }^{1)}$ \\ Dosen Program Studi Teknik Informatika, Politeknik Negeri Indramayu \\ e-mail: estimulyani@polindra.ac.id \\ Eka Ismantohadi ${ }^{2)}$ \\ Dosen Program Studi Teknik Informatika, Politeknik Negeri Indramayu \\ e-mail: ekaismanto@gmail.com \\ Koriah $^{3)}$ \\ Mahasiswa Program Studi Teknik Informatika, Politeknik Negeri Indramayu \\ e-mail: koriah11ag@gmail.com
}

\begin{abstract}
ABSTRAK
Politeknik Negeri Indramayu merupakan salah satu perguruan tinggi yang menerapkan drop out mahasiswa berdasarkan kehadiran dari mahasiswa dan presentase nilai mahasiswa. Kehadiran dan nilai mahasiswa akan dievaluasi pada saat rapat kelulusan yang dilaksanakan pada setiap akhir semester. Kemudian rapat tersebut akan memberikan keputusan status dari mahasiswa. Seringkali mahasiswa yang bermasalah karena kehadiran, tidak mengetahui bahwa seharusnya mahasiswa tersebut mendapatkan peringatan lisan sebelum mendapatkan surat peringatan 1, 2, dan 3. Pada penerapannya peringatan tersebut langsung berupa surat peringatan 1, 2, dan 3. Sehingga dibutuhkan sebuah sebuah sistem yang saling terintegrasi untuk mengatasi permasalahan tersebut. Metode yang digunakan untuk menentukan potensi drop out mahasiswa yaitu dengan metode rule based system. Sistem akan mengirim peringatan melalui sms kepada mahasiswa dan orang tua, sehingga orangtua dapat mengetahui dan memantau kehadiran anaknya. Dengan sistem prediksi ini diharapkan presentase drop out mahasiswa dapat diminimalisir.
\end{abstract}

Kata kunci : sistem, potensi, drop out, rule based system.

\begin{abstract}
Indramayu State Polytechnic is one of the tertiary institutions implementing student dropouts based on student attendance and percentage of student grades. Student attendance and grades will be evaluated at the graduation meeting held at the end of each semester. Then the meeting will give a decision on the status of students. Often students who have problems due to attendance, do not know that the student should get an oral warning before getting warning letters 1, 2, and 3. In the implementation of the warning directly in the form of a warning letter 1, 2, and 3. So we need a system that is mutually integrated to overcome these problems. The method used to determine the potential for student drop outs is the rule based system. The system will send a warning via SMS to students and parents, so parents can find out and monitor their child's presence. With this prediction system it is expected that the percentage of student drop outs can be minimized.
\end{abstract}

Keywords: system, potential, drop out, rule based system. 


\section{PENDAHULUAN}

Perguruan tinggi merupakan penyelenggara pendidikan yang mempunyai standar kompetensi dalam penyelenggaraannya. Salah satu aspek yang mempengaruhi mutu pendidikan adalah mahasiswa. Pendidikan pada perguruan tinggi dikatakan berhasil apabila telah memenuhi tujuan dari pendidikan perguruan tinggi tersebut. Kualitas pendidikan di perguruan tinggi dapat dilihat dari tingginya tingkat keberhasilan mahasiswa dan rendahnya kegagalan mahasiswa. Salah satu indikator kegagalan mahasiswa adalah kasus pemberhentian.

Pemberhentian (drop out) mahasiswa adalah proses pencabutan status kemahasiswaan atas diri mahasiswa, yang disebabkan oleh hal-hal tertentu yang telah diseoakati oleh perguruan tinggi yang bersangkutan. Tingginya jumlah mahasiswa drop out pada perguruan tinggi dapat diminimalisir dengan kebijakan dari perguruan tinggi untuk mengarahkan atau mencegah mahasiswa dari drop out. Politeknik Negeri Indramayu (POLINDRA) merupakan salah satu perguruan tinggi yang menerapkan drop out mahasiswa berdasarkan kehadiran dari mahasiswa dan presentase nilai mahasiswa. Kehadiran dan nilai mahasiswa akan dievaluasi pada saat rapat kelulusan yang dilaksanakan pada setiap akhir semester. Kemudian rapat tersebut akan memberikan keputusan status dari mahasiswa.

Seringkali mahasiswa yang bermasalah karena kehadiran tidak mengetahui bahwa seharusnya mahasiswa tersebut mendapatkan peringatan lisan sebelum mendapatkan surat peringatan 1 , 2 , dan 3. Pada penerapannya peringatan tersebut langsung berupa surat peringatan 1, 2, dan 3. Sehingga dibutuhkan sebuah sebuah sistem yang saling terintegrasi untuk mengatasi permasalahan tersebut. Sistem akan mengirim peringatan melalui sms kepada mahasiswa dan orang tua, sehingga orangtua dapat mengetahui dan memantau kehadiran anaknya.

Sistem prediksi drop out selain dari segi kehadiran juga melihat dari segi nilai mahasiswa, yang pada akhirnya mahasiswa akan mendapatkan status kelulusan dan kriteria kelulusan yang sudah diatur pada peraturan akademik (Peraturan Akademik Polindra, 2012).

Sistem dibangun dalam platform website dan menggunakan metode rule based system untuk mengetahui potensi dini drop out mahasiswa. Sehingga diharapkan presentase drop out mahasiswa dapat diminimalisir dengan menerapkan sistem ini.

\section{Landasan Teori}

\subsection{Peraturan Akademik}

Menurut Peraturan Akdemik Politeknik Negeri Indramayu pasal 7 tentang Status Kelulusan Semester adalah:

1. Status Kelulusan diberikan kepada mahasiswa pada tiap akhir semester berdasarkan hasil evaluasi prestasi akademik, kehadiran dan disiplin.

2. Terdapat 3 jenis status kelulusan pada tiap akhir semester, yaitu:
a. Status Tetap
b. Status Percobaan
c. Status Sementara

3. Pada program pendidikan Diploma 3 pemberian status kelulusan atas hasil evaluasi prestasi akademik ditetapkan berdasarkan kriteria sebagai berikut. 


\begin{tabular}{|l|l|}
\hline $\begin{array}{l}\text { Status } \\
\text { Kelulusan }\end{array}$ & Kriteria \\
\hline Tetap & $\begin{array}{l}\text { IPS } \geq 2,00 \text { dan Jumlah sks nilai D } \\
\leq 4 \text { dan Tidak memiliki nilai E }\end{array}$ \\
\hline $\begin{array}{l}\text { Status } \\
\text { Percobaan }\end{array}$ & $\begin{array}{l}\text { IPS } \geq 2,00 \text { dan Jumlah sks nilai D } \\
>4 \text { dan Tidak memiliki niliai E } \\
\text { atau } 1,75 \leq \text { IPS }<2,00 \text { dan Jumlah } \\
\text { sks nilai D } \leq 8 \text { dan Tidak memiliki } \\
\text { nilai } \mathrm{E}\end{array}$ \\
\hline $\begin{array}{l}\text { Tidak } \\
\text { Lulus }\end{array}$ & $\begin{array}{l}\text { IPS }<1,75 \text { atau Jumlah sks nilai D } \\
>8 \text { atau Status percobaan } 2 x \\
\text { berturut }- \text { turut atau memiliki nilai } \\
\text { E }\end{array}$ \\
\hline
\end{tabular}

Tabel 1. Kriteria status kelulusan

4. Status percobaan dan pemberhentian sementara dari kegiatan akademik dapat diberikan kepada mahasiswa yang melewati batas maksimum ketidak hadiran dalam satu semester atau satu tahun ajaran.

5. Pemberian status kelulusan atas dasar waktu ketidak hadiran ditetapkan berdasarkan kriteria sebagai berikut:

a. Status percobaan diberikan kepada mahasiswa yang memiliki total ketidakhadiran melebihi 160 jam dalam 1 semester.

b. Pemberhentian sementara dari kegiatan akademik akan diberikan kepada mahasiswa yang memiliki ketidak hadiran melebihi 320 jam dalam satu tahun.

6. Status Tidak Lulus dapat diberikan pada mahasiswa yang melanggar Peraturan Tata Tertib dan Disiplin. Jenis dan sanksi atas pelanggaran diatur dalam pasal tersendiri.

\subsection{Rule Based System}

Rule Based System dibuat untuk memecahkan masalah dengan aturan yang dibuat berdasarkan pengetahuan dari pakar. Aturan tersebut memiliki kondisi (if) dan tindakan (then). Peraturanperaturan tersebut akan dimasukkan ke dalam mesin aplikasi. Dengan beberapa penyocokan pola dan aturan dari applier. Mesin akan mecocokkan dengan peraturan yang ada dan menentukan aturan yang berhubungan. Rule Base mudah untuk digunakan dan dimengerti, namun rule base tidak dapat membuat peraturan baru atau memodifikasi peraturan yang ada dengan sendirinya karena rule base tidak dirancang untuk dapat belajar (Edo Pangkatodi, Liliana, dan Gregorius Setiabudhi, 2016).

Rule Based System adalah tipe khusus dari sistem pakar, yang terdiri dari seperangkat aturan 'if-then' dan dapat diterapkan sebagai sistem pendukung keputusan diberbagai bidang seperti kesehatan, transportasi dan keamanan. Rule base system dapat dibangun berdasarkan pengetahuan ahli dan pakar. Pengembangan Rule Base System dimulai pada tahun 1960-an tetapi menjadi popular dijepang pada tahun 1970-an dan 1980-an. Rule Base System dapat dikategorikan dalam aspek-aspek berikut: jumlah input dan output, tipe input dan nilai output, tipe struktur, tipe logika, tipe aturan berbasis, jumlah machine learners dan jenis lingkungan komputasi (H. Liu, A. Gegov dan F. Stahl, 2014). 


\section{METODE PENELITIAN}

Metode prediksi yang digunakan untuk menentukan potensi drop out mahasiswa yaitu menggunakan metode rule base system.

Format aturan pada rule base system pada umumnya adalah if $<$ kondisi $>$ then $<$ kesimpulan $>$. Dimana kondisi mewakili premis atau fakta dan kesimpulan mewakili aksi dari premis yang diberikan. Kondisi bisa berupa sebuah premis atau set premis yang terhubung dengan operator logika $A N D$ dan $O R$. Kesimpulannya bisa berupa tindakan untuk diambil atau fakta yang disimpulkan dari premis yang diberikan (Sugiharto, WH dan Imam Ghozali, 2017). Berikut merupakan perencanaan data rule untuk menentukan potensi drop out mahasiswa:

1. Kaidah Produksi Rule Status

Mahasiswa

a. Rule 1 Tetap

IF IPS $>=2.00$

$A N D$ Jumlah sks nilai $\mathrm{D}<=4$

$A N D$ nilai $\mathrm{E}=0$

THEN Tetap

b. Rule 2 Percobaan

IF IPS $>=2.00$

$A N D$ Jumlah sks nilai $\mathrm{D}>4$

$A N D$ nilai $\mathrm{E}=0$

OR $1,75<=$ IPS $<2.00$

$A N D$ Jumlah sks nilai $\mathrm{D}<=8$

$A N D$ nilai $\mathrm{E}=0$

THEN Percobaan

c. Rule 3 Tidak Lulus

IF IPS $<1.75$

$O R$ Jumlah sks nilai $\mathrm{D}>8$

$O R$ Percobaan $=2 \mathrm{x}$ berturut-berturut

$O R$ nilai $\mathrm{E}>0$

THEN Tidak Lulus
2. Kaidah Produksi Rule Status Kehadiran Mahasiswa

a. Rule 1 SP Lisan 1

IF $\mathrm{T}>=4$ jam

$A N D \mathrm{~T}<8$ jam

THEN SPL 1 Untuk SPT 1

b. Rule 2 SP Lisan 2

IF $\mathrm{T}>=8$ jam

$A N D \mathrm{~T}<12$ jam

THEN SPL 2 Unutk SPT 2

c. Rule 3 SP Lisan 3 dan SP Tertulis 1

IF $\mathrm{T}>=16 \mathrm{jam}$

$A N D \mathrm{~T}<22$ jam

THEN SPL 3 dan SPT 1

d. Rule 4 SP Lisan 1 menuju SPT 2

IF $\mathrm{T}>=22$ jam

$A N D \mathrm{~T}<28$ jam

THEN SPL 1 menuju SPT 2

e. Rule 5 SP Lisan 2 menuju SPT 2

IF $\mathrm{T}>=28$ jam

$A N D \mathrm{~T}<32$ jam

THEN SPL 2 menuju SPT 2

f. Rule 6 SP Lisan 3 dan SPT 2

IF $\mathrm{T}>=32$ jam

$A N D \mathrm{~T}<38$ jam

THEN SPL 3 dan SP Tertulis 2

g. Rule 6 SPL 1 menuju SPT 3

IF $\mathrm{T}>=38 \mathrm{jam}$

$A N D \mathrm{~T}<44$ jam

THEN SPL 1 menuju SPT 3

h. Rule 7 SPL 2 menuju SPT 3

IF $\mathrm{T}>=44$ jam

$A N D \mathrm{~T}<48$ jam

THEN SPL 2 menuju SPT 3

i. Rule 9 SPL 3 menuju SPT 3 dan

DO

IF $\mathrm{T}>=48$ jam

THEN SPL3, SPT 3, dan DO

Dari hasil kaidah produksi rule yang telah dibuat, kemudian diterapkan pada perancangan sistem UML (Undefined Modelling Language). Use Case Diagram 
memperlihatkan hubungan antara aktor dan use case. Aktor merepresentasikan seorang user yang berinteraksi dengan sistem (Sri D dan Romi S. W, 2003). Use Case Diagram pada sistem ini memiliki 4 aktor yaitu admin baak, admin jurusan, sebagai user dari platform website sedangkan orang tua mahasiswa dan mahasiswa sebagai user penerima sms. Use case diagram dari sistem potensi prediksi dropout mahasiswa dijelaskan sebagai berikut:

\section{Gambar 2. Use Case Diagram}

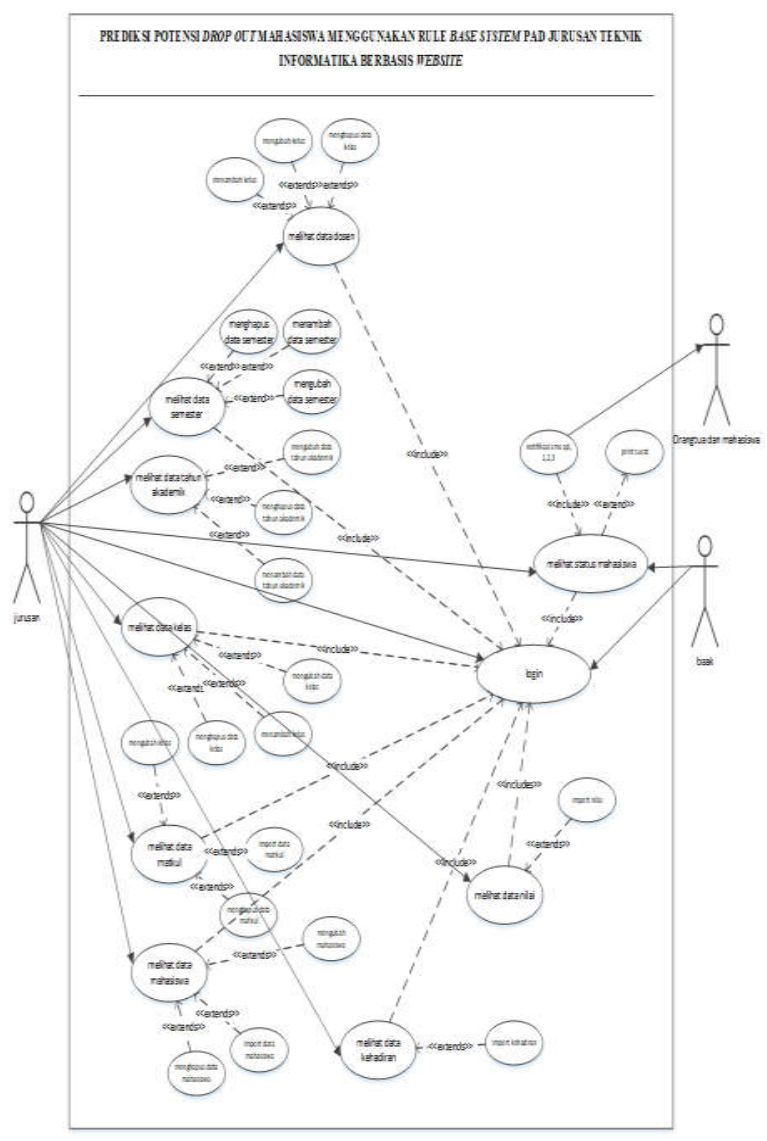

\section{HASIL DAN PEMBAHASAN}

Penelitian ini menghasilkan sistem prediksi potensi drop out mahasiswa dengan menggunakan metode Rule Base System yang dapat membantu akademik untuk menentukan status mahasiswa. Berikut adalah beberapa tampilan utama yang ada pada sistem ini:

1. Halaman Login

Gambar 2. Halaman login

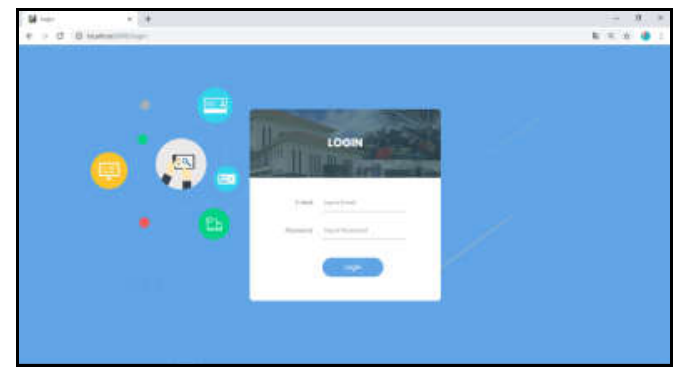

Halaman login merupakan tampilan awal pengguna. Pengguna harus mengisi form login dengan mengisi email dan password agar dapat masuk ke halaman utama.

2. Halaman Data Mahasiswa

Gambar 3. Halaman data mahasiswa

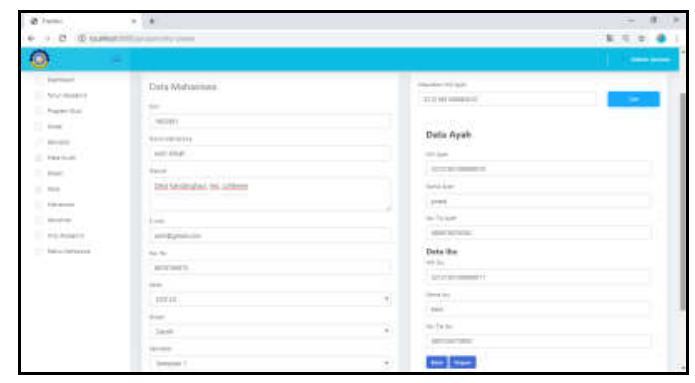

Halaman mahasiswa menampilkan form untuk mengisi data mahasiswa. Selain itu, pada halaman ini menampilkan form untuk mengisi data orang tua. 
3. Halaman Nilai

Gambar 5. Halaman nilai

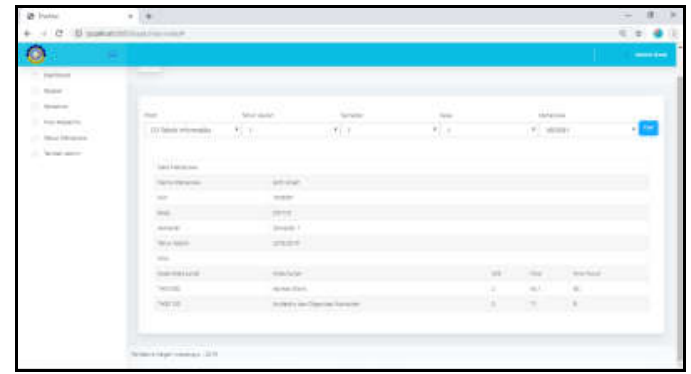

Halaman nilai menampilkan data nilai yang sebelumnya sudah diupload oleh admin jurusan. Nilai yang diupload sesuai dengan mata pelajaran yang diikuti oleh mahasiswa.

\section{Halaman Kehadiran}

Gambar 6. Halaman kehadiran

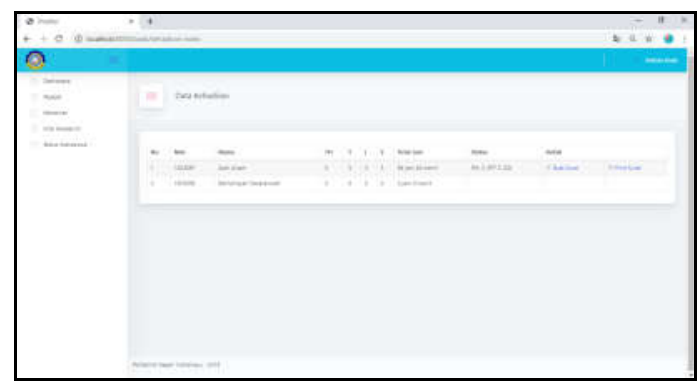

Halaman kehadiran menampilkan hasil rekap kehadiran yang diupload oleh admin jurusan. Halaman ini menampilkan jumlah ketidakhadiran (th), terlambat (t), sakit (s) dan izin (i). Menampilkan total jam dari setiap keterlambatan dan ketidakhadiran mahasiswa kemudian mahasiswa akan mendapat status berdasarkan kehadiran.
5. Halaman Status Mahasiswa

Gambar 7. Halaman status mahasiswa

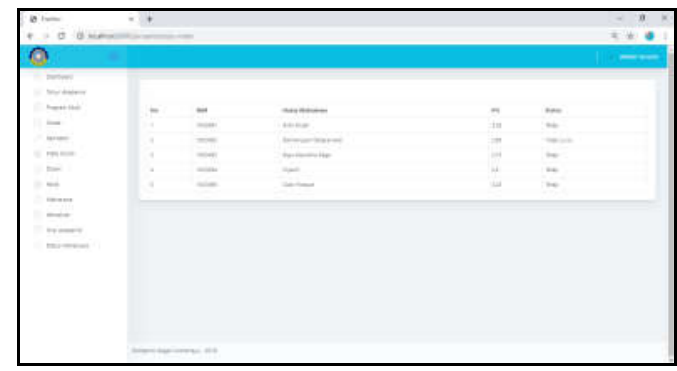

Halaman status mahasiswa menampilkan data status mahasiswa yang di dapat dari nilai yang sebelumnya sudah diupload oleh admin jurusan.

6. Halaman Buat Surat Peringatan

Gambar 8. Halaman buat surat peringatan

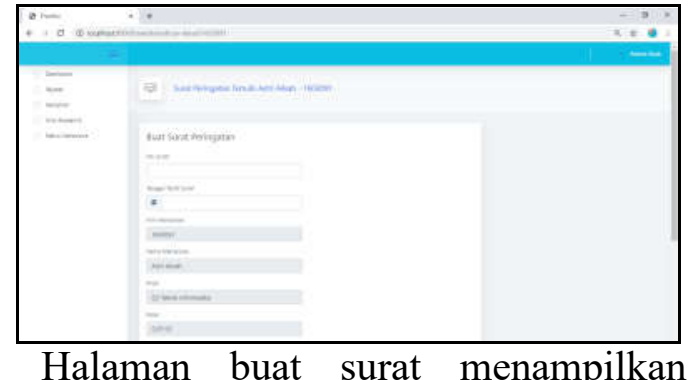

form untuk membuat surat. Admin hanya mengisi form nomor surat, tanggal terbit surat, tanggal pertemuan dengan orangtua dan jam pertemuan dengan orangtua, data mahasiswa akan diisi secara otomatis dan ketika admin ingin mencetak data, maka data-data yang diperlukan pada surat yang akan dicetak akan ditampilkan sesuai dengan data dari surat yang sudah dibuat sebelumnya pada form buat surat. 
7. Tampilan Surat Peringatan

Gambar 9. Halaman surat peringatan

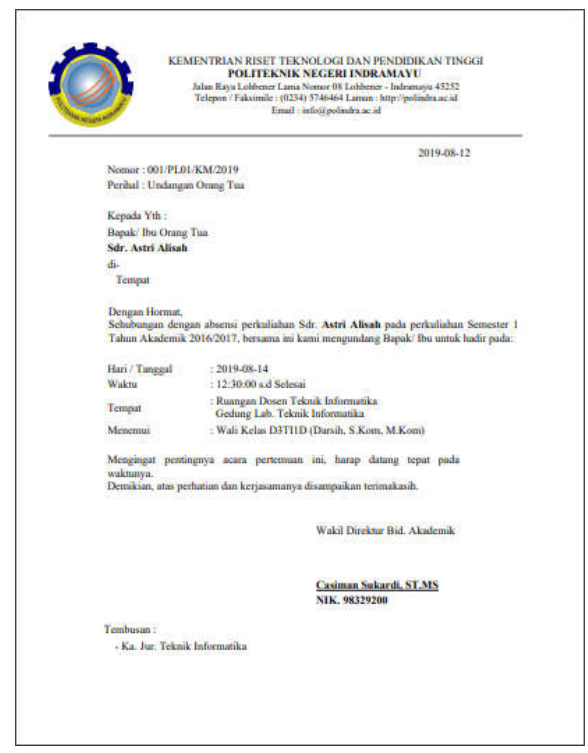

Surat didapatkan ketika mahasiswa memiliki total keterlambatan dan ketidakhadiran yang lebih atau yang melanggar peraturan, dan mendapat status peringatan tertulis.

\section{Tampilan SMS Peringatan}

Gambar 10. Halaman sms peringatan

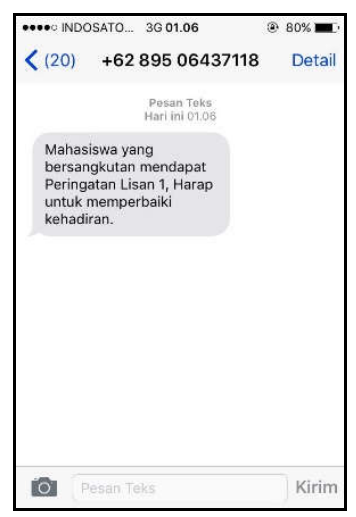

Gambar 10. merupakan hasil screenshots dari notifikasi sms surat peringatan lisan 1 menuju surat peringatan tertulis 1 pada nomor mahasiswa dan orang tua mahasiswa.

\section{KESIMPULAN DAN SARAN}

Kesimpulan yang didapat dari penelitian ini setelah mengumpulkan data, menganalisis kebutuhan, membangun sistem dan melakukan pengujian sistem yang dihasilkan adalah sebagai berikut:

1. Sistem prediksi drop out ini dapat membantu admin memberikan peringatan lisan, dengan implementasi dari peringatan sms yang dikirimkan dari sistem kepada mahasiswa dan orang tua mahasiswa yang bersangkutan.

2. Pemberian status mahasiswa berdasarkan perhitungan yang mengacu pada peraturan peraturan akademik Politeknik Negeri Indramayu tahun 2012.

\section{DAFTAR PUSTAKA}

Dharwiyanti, Sri dan Wahono, Romi S. (2005)," Pengantar Undefined Modeling Language (UML)".

Liu, Han, Alexander G. and Frederic S. 2014. "Categorization and Construction of Rule Based Systems".

Pangkatoldi, Edo. Liliana dan Setiabudhi, Gregorius, 2016. "Implementasi Rule Base System dan Fuzzy Logic Artifical Intelligence pada Game Kartu Capsa”. Vol. 4. No. 1.

Sugiharto, Wibowo Harry dan Ghozali, Imam. 2017. "Online Electronic Devices Monitoring System Menggunakan Rule Based System". Vol. 21, No. 1, Hal. 22.

Tim Penyusun, 2012. "Peraturan Akademik", Politeknik Negeri Indramayu 